\title{
Learning in a Content-Based, Collaboratively Structured Course: The Experience of an Adult ESL Learner
}

\section{Merrill Swain and Laura S. Miccoli}

In this article the emotive, social aspects of learning ESL in small group settings are explored. The feelings and beliefs of one learner, an adult Japanese woman, are captured as she reflects on her classroom experiences. It is argued that her conscious reflection about her negative emotions and their sources allowed her to act on them, resulting in enhanced second language learning. It is also argued that it may be as important to help learners deal with the social dimensions as the cognitive dimensions of second language learning in order to experience success as a second language learner.

\section{Introduction}

An interactively organized, content-based classroom is considered to provide a useful setting for second language acquisition. With a few exceptions, we know little about how learners react to being in such a situation. This article describes the reactions of one learner, Hiroko (her choice of name), to her experiences in a collaboratively organized course. Although her experiences are unique to her and to the course, we believe that there are important conclusions to be drawn. In particular, we wish to suggest that collaborative learning involves powerful emotions that can affect its outcome. Awareness of them and reflection about them may be as essential to successful learning as is conscious reflection about the cognitive aspects of learning.

\section{Collaborative Learning}

Collaborative learning, organizing classes into small groups for the discovery and mastery of academic content, has been a major movement in mainstream education (Kagan, 1989; Sharan \& Sharan, 1992; Slavin, 1990). A considerable body of research suggests multiple benefits of well-structured collaborative learning (for a synthesis, see, e.g., Slavin, 1991) relative to more traditional teacher-fronted classrooms. The benefits of collaborative learning include higher academic achievement, improved intergroup relations, more positive attitudes toward school, and enhanced self-esteem. Most of this research has been conducted with children and young adolescents.

In recent years attention has been paid to possible advantages collaborative learning might have in bilingual education contexts (Holt, 1993; Kagan, 
1986; Kessler, 1992), and specifically for second language acquisition (Coelho, 1992; Long \& Porter, 1985; Pica, Holliday, Lewis, \& Morgenthaler, 1989). Collaborative learning has the potential of engaging students in extended discourse about topics of genuine interest. Through their discourse, learners may use a wider range of linguistic functions than in typical teacher-student interactions, and they may stretch their linguistic resources to the limit as they attempt to express cognitively complex ideas. Furthermore, their discourse will probably entail the negotiation of meaning and form, providing the opportunity to increase the comprehensibility of their input and the accuracy of their output (Swain, 1993).

The graduate level course in which Hiroko was a student was taught by one of the authors (Swain). Entitled "Collaborative Learning in Second Language Classrooms," it was a 13-week course, meeting each week for approximately three hours. The goals of the course were stated as follows: (a) to understand the rationale for collaborative learning in classrooms with second language learners, particularly as it relates to second language acquisition (SLA) theory; and (b) to experience collaborative learning in order to understand its advantages and disadvantages. Students were required to keep a journal throughout the course, making at least one entry a week.

The course was divided into two parts. During the first six weeks, students read and discussed articles that dealt with the SLA theory and research that provides the rationale for using a collaborative approach with second language learners. This part of the course was organized according to the Jigsaw strategy (Aronson, Blaney, Stephan, Sikes, \& Snap, 1978). Students were assigned one of several articles that they would eventually be expected to teach to their peers. Initially the students who read the same article got together (usually in groups of two or three) in "expert groups" and discussed (with the help of a set of guiding questions distributed at that time) the contents of the article until they felt confident about their understanding of its content. Subsequently students moved into "home groups" in which each member was responsible for teaching about his or her article to the other students, with the final goal of being able to respond to a set of questions that typically involved the synthesis of material across the articles.

In the second half of the course, with the exception of Hiroko, students were grouped according to their interests: ESL or FSL (French as a second language); children, adolescents, or adults. Although Hiroko had taught EFL to children in Japan, she was grouped with the adult ESL group for two reasons: (a) she herself was an adult ESL learner; and (b) one of the students in that group had had extensive experience in Japan and had shown both interest in, and support of, Hiroko. During this part of the course the students designed, conducted, and reported on (both orally and in a final written assignment) an investigation of some aspect of collaborative learning. Hiroko's group examined the quantity and quality of negotiation of 
meaning that occurred among advanced ESL adult learners in two activities. One activity was a highly structured collaborative task, whereas the other was an unstructured discussion task.

At the end of the term the 18 students anonymously completed an evaluation of the course. In order to provide a context to aid in the interpretation of Hiroko's reactions to the course, two key questions and their results are given here.

One question asked about students' satisfaction with the course. A fourpoint scale was provided from 1 (very low) to 4 (very high). The average rank of the 17. students in the course (not including Hiroko) was 3.8. Hiroko ranked her satisfaction level at 3 .

Another question asked about the effect of the collaborative learning experience on the student's self-esteem. A five-point scale was provided from "greatly lowered my self-esteem". to "greatly enhanced my self-esteem." Two students responded with "somewhat lowered my self-esteem"; five students responded with "didn't affect my self-esteem one way or another"; three students responded with "somewhat enhanced my self-esteem"; and seven students responded with "greatly enhanced my self-esteem." Hiroko replied that it had initially "greatly lowered my self-esteem." but that by the end of the course it had "somewhat enhanced my self-esteem."

\section{Research Methodology}

There have been demands for a more active role of the learner in SLA research. Allwright (1988) calls for "forms of investigation that would not only be productive for learners but that would also bring the learner in as a partner in the research enterprise" (p. 258). Van Lier (1988) states that "few researchers ... have solicited learners' views of their language learning careers" (p. 79). Finally, Johnson (1992) points out that "there is surprisingly little ethnographic work on the language learning and cultural adjustment of adolescents and adults relative to the many experimental and correlational studies" (p. 135).

The incorporation of these features into a study of foreign language learning in a university setting in Brazil is being planned by one of the authors (Miccoli) as her doctoral research. In order to further our understanding of how the research might proceed, and the nature of the data that might be obtained, we asked Hiroko if she would be willing to collaborate with us in a pilot study. Both she, and subsequently the entire class, agreed to participate.

During class time Hiroko always worked in a group context. Early in the term her group(s) was audiotaped at one session and videotaped the following week. Then, near the end of the term, her group was videotaped again. 
During these sessions Miccoli observed, taking field notes and generating questions to ask Hiroko during their interview sessions.

Seven interviews were held over a two-month period. The objective of the first interview was for the researcher and Hiroko to become acquainted. At the second, fifth, sixth, and seventh interviews, the stimuli for discussion were the tapes and field notes. At the third and fourth interviews, the discussion stimuli were notes each participant had written about the processes of learning another language. A final eighth interview was held six weeks after the last observation so that Hiroko could comment on the transcripts of the interviews and a preliminary analysis of the data. The results-a consented description of the process she experienced as a learner in the collaborative learning course--are based on this joint analysis. This description documents, in particular, the emotive facet of the stages that Hiroko moved through as a learner of both content and language, in a situation in which she was the least able linguistically.

\section{Hiroko}

Hiroko, a native of Japan, began to study English in school at age six. She graduated from a Japanese university in English in 1981. After graduating, she tutored young children in English at home. Hiroko arrived in Toronto in March 1992. Her husband, a research fellow, came to Toronto for a two-year stay. She applied to start an MEd program, was accepted, and started in September 1992. "Collaborative Learning in Second Language Classrooms" was her third course, taken in the second term beginning January 1993. At the time of this study, Hiroko was 35 years old, and her proficiency in English was that of an intermediate ESL learner.

Hiroko reported that her first term as a graduate student represented her "silent period." She acknowledged that she could not understand most of the lectures and that she could not/would not speak in class. She knew her studies were a challenge for her, but she was determined to overcome her difficulties. It was for the opportunity to develop her fluency in English as well as to learn more about herself as a language learner that she agreed to participate in this study.

An analysis of Hiroko's English linguistic development over the period of this study has not been conducted. However, there is no doubt, either in the minds of the present authors or Hiroko herself, that she made considerable progress. Six points are worthy of note. First, by listening to the second and last interview tapes, one can readily hear the increase in Hiroko's fluency. Second, Hiroko reported that by the end of the term she could understand $50-80 \%$ of the class discussion, except when she was tired. This compares favorably with her self-report at the beginning of the term that she had not been able to understand much of the lectures in her class the previous term. 
Third is the remarkable appetite Hiroko showed for new, more colloquial expressions:

Laura: You're not that thrilled with this project. This project is not making your heart beat.

Hiroko: That's new phrase for me "heart beat" (laugh). I like it.

Fourth, an increase in self-correction was observed in the last few interview sessions:

Hiroko: We met maybe most than other groups ... more than other groups.

Fifth, in the last few sessions, Hiroko spoke a great deal about her need to learn ways of interrupting and becoming part of the ongoing conversation. The quote in which she expresses her understanding of the use of "hang on" to interrupt an ongoing discussion in a meeting is an excellent example. Hiroko's thoughts on this are well reflected in the following quote:

Hiroko: Maybe the next step is find a chance to speak. Very difficult for me. It is not our culture.

Finally, over the course of the term, Hiroko shifted from writing her notes in Japanese to writing them in English.

Laura: Have your notes changed? Do you still write part of your notes in Japanese or are you writing them mostly in English now?

Hiroko: I am writing most of them in English ... I realized that I should take notes in English.

\section{Data Analysis}

Hiroko appears to have gone through three rather distinct phases over the course of the term. Each phase is marked by a different dominant emotion that Hiroko reported feeling. Phase one was marked by feelings of anxiety; the feeling associated with phase two was depression; and the third phase was marked by feelings of happiness. Each of these phases was linked to the nature of the task in which Hiroko was involved, the content of the material being considered, and the barriers that language placed on her group involvement. We wish to suggest that through the interview process, Hiroko became aware of her emotions and their sources, resulting in her ability to deal constructively with them. Without this conscious reflection on what she was living through, she might have left the course depressed and lacking in self-esteem. Finally, it is important to note the role of Hiroko's cultural background in her adaptation to the course format. 
We begin with a brief examination of the importance of Hiroko's Japanese background in her involvement in a collaboratively structured class. This is followed by a description of the phases Hiroko went through during the term in which illustrative comments are excerpted from the interviews.

\section{Culture}

Over the term, two different ways in which Hiroko's cultural background affected her learning became apparent. First, according to Hiroko, the prevailing way of working in school and on classroom assignments in Japan is individually. In the first entry in her journal, she mused: "Can I be collaborative?" She felt her background had not prepared her to participate in small group class discussions.

Because [when] I used to be a student, just sit and get some information from the professor. We, most of Japanese, used to such situation, so to get into the discussion is hard for me as a student. (Int. 4)

This problem of "getting into the discussion" plagued Hiroko throughout the course. Sometimes she wanted to enter the discussion but could not because "they had the floor"; other times, "some of them asked me to speak more ... they tried to make some space for me to talk ... but I don't want to speak when I was pointed [at]."

Second, Hiroko's beliefs about second language learning and teaching were strongly influenced by her EFL experiences in Japan. She believed that learning is a goal-oriented activity and is highly dependent on the teacher.

Maybe because I'm Japanese. [I always say] the purpose of the student to go to ESL is not to chat or not to speak with other peers, even if they use only English, they want to get something new or some ideas or something about English. (Int. 4)

This belief strongly affected her attitude toward the project she was involved in during the second half of the term. She doubted that students in an ESL class would profit from an interactive collaborative setting and thus she claimed the study held little interest for her. As it turned out, her beliefs were shattered because the students in the ESL classes in their study not only enjoyed the group work, but felt that they had learned something from it. It is possible that this realization was an important stimulus in her own thinking that maybe she was learning through her own collaborative experiences.

Phase one. During the first six weeks of the course, when it was structured according to Jigsaw principles, Hiroko's overriding emotion was anxiety. Words she used about this period were "afraid," "scared," "frightened," "nervous," and "worried." She felt responsible for her classmates' understanding of the articles she had read. Because she found both tasks-reading 
and explaining-difficult, the amount of responsibility this represented made her anxious.

An analysis of the data during this period shows that Hiroko was worried about summarizing in her own words the articles she read. The possibility that she might be responsible for her classmates' misunderstanding of important points in the readings was a major concern for her.

I apologized very much to all of them that I met in my small groups, because I felt so [much] responsibility that I couldn't explain well. So maybe some of them were surprised about my apologies. And they noticed that I felt so bad. (Int. 2)

I was scared (laugh) that I had to explain by my own words. The responsibility, the amount of responsibility, scared me. (Int. 8)

[this week] my anxiety became serious. There was a quiz ... it was my fault if they could not answer the quiz. (J. 4)

Throughout this time, Hiroko was aware of the support and sympathy she was getting from her fellow students: "[they] were very careful and had sympathy with me very much."

Phase Two.As the course moved from a study of relevant literature to the design and implementation of an investigation about an aspect of collaborative learning, Hiroko's dominant emotion was depression.

Awful. I would like to withdraw from this class. (J. 7)

Now I feel more depressed. (Int. 4)

The source of her feelings of depression was her lowered self-esteem. In her group she felt unable to contribute. The situation was quite different than in the first phase where although she felt anxious because she felt that her linguistic abilities did not allow her to carry out successfully her responsibilities, now she felt she did not know enough to carry them out: "I have the responsibility to contribute but I have no source (= knowledge/experience)."

I can do what I was told. If the teacher told me to read this assignment, and to explain something, I can do or I'll try to do. However, now I

have to find by myself (= I have to have my own opinions). (Int. 4)

Furthermore, when Hiroko tried to contribute her views, she felt that her ideas were rejected.

My point or my opinion or my understanding is out of point ... doesn't work ... doesn't fit. (Int. 4)

My part was to make questionnaire and I prepared two or three pages but it was useless. All of them were useless. I was so disappointed. (Int. 4) 
I could do nothing on the project but just sit down and listen to my fellow students in quiet. (J. 8)

At this point, Hiroko blamed much of her inability to contribute on her lack of interest in the project. She provided two different reasons for her lack of interest: first, she had been assigned to this group that was interested in adult ESL learning when her interest was in ESL children. Second, for a research question, she was interested in comparing a teacher-fronted class with a collaborative class. Instead, her group decided to focus on the differences between unstructured and structured collaborative practices. She kept silent about her interests, however, fearing that she would not know how to develop them into a research project.

I was interested in observing the difference between lockstep situation and cooperative situation. I had no practical idea about observing my interested difference. So, I knew that if I asked them that, they would ask me about the practical idea, so I stopped speaking out. (Int. 5)

During this phase Hiroko expressed feelings of "irritation" and "anger" with her peers: "the inferiority make me irritated."

All in all, this was a difficult period for Hiroko. It is, of course, impossible to know how Hiroko might have changed over the rest of the term, or even if she would have, without the intervention of the interviewer. Throughout the interviews one goal had been to encourage Hiroko to reflect on her experiences as a language learner and to gain insight about how her perceptions influenced her language learning. Thus the interviewer began to focus on helping Hiroko through this painful phase.

Transition phase.The interviewer's strategy was to encourage Hiroko to think through what the source of her unhappiness was, and to suggest that she discuss it with her group or the professor. Hiroko's analysis, partly reflected in the quotes noted above, is succinctly summarized in a statement she made during the sixth interview: "No one expect me anything [no one expects anything of me]." Pushed by both the interviewer and the professor, Hiroko finally decided to summon all her courage and talk to her group members about her feelings. In a sense this was the turning point of Hiroko's emotional downslide. Beforehand, she had said:

So, maybe they cannot understand what I feel and maybe I cannot understand what they are feeling. (Int. 6)

Following her discussion with them, she began to recognize that there were two sides to her dilemma:

And they feel guilty for me, but I feel guilty for them too, no? (Int. 7)

Her group's response had been to express their concern for Hiroko's feelings of worthlessness, yet to insist that she must be more of a participant 
in their group discussions. They would make an effort to give her time to express her ideas, but she would have to insert herself into the conversation more aggressively. Together they would distribute work making sure that each member contributed according to his or her strengths. They assured Hiroko that she was part of "the team" and that they wanted her to continue to work with them. Hiroko responded positively to this peer reaction:

The idea that "made my heart beat" was that I did not do anything FOR them, but I worked WITH them. (J. 10)

In a cooperative learning setting ... some are good at leading the team; some are good at modifying. Some are familiar with theories, some with practical study. As a result, though each has a little power, each can achieve better as a group than as individuals. (J.10)

From this point, Hiroko's feelings began to change positively.

Phase three. This phase is dominated by feelings of happiness. As a result of the combined, conscious efforts of Hiroko and her peers, her participation in the group research project was enhanced. Furthermore, as work on their project continued, Hiroko found she had considerable skills to contribute. The need for someone with skills in math for the data analysis and the production of graphs on the computer changed Hiroko's sense of lowered self-esteem into self-confidence.

I could make a graph, use my math knowledge, so I'm happy now. All, most of the things have changed in the direction of the good way and I could contribute to the group. I'm happy. (Int. 7)

The presentation has finished. It was well done. Even though I had a very small part in it, it was enough for me to try my best ... I did not memorize and I needed a few notes to read, but I did my part very calmly. (J. 12)

I came to this point with very many ups and downs. (Int. 8)

At this point, more confident of herself, Hiroko's perception of what she had learned began to change. No longer did she think she was not learning anything and should drop out of the course. Rather, she came to recognize that she had made progress in understanding the course content, in English, and in the social dynamics of working together.

We learned collaborative learning through our project. We argued sometimes but we overcome ... overcame. We worked very hard. We lost our way during the project, but everyone thought, and we saw the profit.

(Int. 7)

I learned many things from my group. "Hang on" is a good one to stop a meeting. Maybe it's better than "please listen to me." (Int. 7) 
In synthesizing her feelings, Hiroko stated:

There was a bad situation which caused the best. You encouraged me. I have a little bit confidence. I found my strengths and they admired me, and I have more confidence, and I ready to do or to go one more step. I don't know exactly the new stage. I can do more. Maybe it's hope. (Int. 7)

\section{Discussion}

In this article we focus on the emotions an adult learner experienced as she participated in a content-based, collaboratively organized course. The course was not intended to be an ESL one, but its structure was such that it should have provided, according to theoretical and empirical accounts (Kagan \& McGroarty, 1993; Long \& Porter, 1985), an excellent environment for second language acquisition to occur. It was also an environment where academic achievement has been demonstrated to be enhanced and where higher selfesteem is a typical outcome (Fathman \& Kessler, 1993). In this discussion we focus on the implications for both collaborative learning and second language learning.

\section{Collaborative Learning}

Most of the theory and research concerned with collaborative learning has involved young children or adolescents. Furthermore, with few exceptions (e.g., Mulleret, 1992), adult second language learning in collaborative settings has not been studied. For this reason alone, it is of interest to examine a learner's progress through such a course from his or her perspective.

The particular course in which Hiroko was enrolled was being taught for the first time and introduced to the students as an experimental course. The students were asked to provide feedback to their instructor (directly or through their journals) about course content and learning processes in order to modify current practice if that seemed necessary, and to improve the course for the next time it would be taught.

In developing the course syllabus, the instructor wanted the learning process to model as closely as possible the content the students were learning. The content was drawn almost exclusively from the second language literature rather than the collaborative literature. Therefore, it paid relatively little attention to the social side of group learning, which is a major focus of attention in much of the collaborative learning literature (Johnson \& Johnson, 1991). Nevertheless, twice during the term the students were asked individually to complete a questionnaire about each of their group peers that asked whether each peer used his or her work time effectively, fulfilled individual work responsiblities, was supportive of and helpful to group members, and helped to resolve conflicts among group members. The first 
time the questionnaires were completed the groups discussed them among themselves; the second time they were handed in to be included as a portion of each student's final grade. It was anticipated that, although potentially difficult to do, discussing these questionnaires would help groups work through difficulties they might be having. However, almost without fail students commented either directly to the instructor or in their journals about the need to be provided with more help with group functioning: "Even though we're adults, we are experiencing conflicts. I think we need to be taught how to resolve them." "Who would have thought that as mature adults we would need instruction about how to behave?" "If we need help with getting along, imagine how much help our students need." "It is surprising to me, but we need to be helped to work through our differences." "We need to be taught how to involve non-participants."

\section{Second Language Learning}

Renewed interest in the role of consciousness/awareness in second language learning is evident in recent publications such as McLaughlin (1990), Schmidt (1993), and van Lier (1991). This work, however, focuses on the cognitive requirements for the linguistic processing of language. Relatively unexplored is the role that consciousness might have on the more social processes of language learning. In the present study our interpretation of the data revealed that debilitating emotions of anxiety (Horowitz \& Young, 1991) and depression led Hiroko to believe that she was not able to learn more English in this context: "I should go to ESL, not to this class." "I feel blocked."

Although not identical, Hiroko experienced similar feelings to those expressed by Brazilian EFL adult classroom learners in their journals (Miccoli, 1987). In that study, the learners began with feelings of inadequacy and inferiority. Like Hiroko, they were unsure about class dynamics, their performance, and the ways their classmates saw them. Furthermore, like Hiroko, some of the EFL learners even considered dropping out of the course. Moreover, realizing the unavoidable ups and downs in the learning process and coming to understand that ultimately one is responsible for one's own learning, followed a period in which students gradually gained confidence in themselves in the classroom situation. It is interesting that the recognition of the "bumpy road" to learning also occurred for Hiroko only after she had developed confidence in herself.

In the EFL study, the process of consciousness-raising through journalwriting was complemented with an opportunity to talk about whatever emerged in the journals in classroom discussions. Students brought their journals to class, relevant issues were presented by class members, and the teacher led the discussion, which could range from learning problems to classroom issues. In Hiroko's case the interviews served the same function. 
That is, the interaction served as an opportunity to deepen the reflection process, to pinpoint important issues, and to identify possible actions. In both cases, we are suggesting, second language learning was enhanced both directly and indirectly by the role of awareness in the process.

\section{Conclusion}

In this article, we hope to have captured the role of the social aspect of language learning in a collaborative setting. By focusing only on the cognitive processes thought to result from interaction between speakers, half of the equation is lost. Hiroko came close to dropping out due to her lowered self-esteem. She might have left the course emotionally drained and with the perception of herself as a poor language learner. Through conscious reflection about what she was experiencing she was able to understand the social as well as the cognitive dimensions of a collaborative learning course and act on them.

Through its methodology, this study has tried to meet some of the demands of second language acquisition researchers for more learner involvement in the research process. As a result of the methodology, in which Hiroko was asked to reflect on her own learning, be it of content or language, prompted by tapes and videos of her own classroom participation, the research provided an insider's perception of classroom language learning and the cultural adjustments she struggled with in order to be a classroom participant. Furthermore, the research was, according to Hiroko, beneficial to her as a second language learner.

This suggests that in the broad context of collaborative learning, an important element for adults may be consciousness-raising about what the group is accomplishing, how it is being accomplished, and whether it could be accomplished in more satisfactory ways. We would even suggest that adult learners might be expected to reflect on what it is about group learning that is supposed to help them learn, and focus their attention on ensuring that it occurs.

Finally, group dynamics in a collaborative situation is not as simple as it seems. Individual expectations have to be negotiated with those of each group member. The role of awareness in this social aspect of collaborative and second language learning seems important in accomplishing this. Raising Hiroko's awareness about her feelings and their sources provided her with the opportunity to act on them. As a result she became more assertive in interacting with her peers, consciously trying to gain entry to conversations and to express her ideas and opinions. As a consequence she became active in noting the ways her peers accomplished these linguistic functions and tried them out herself. In effect, she began to take responsibility for her own learning, which in turn had a positive effect on her understanding of the role of collaboration in learning a second language. 


\section{The Authors}

Merrill Swain is a professor in the MLC at OISE. Her interests include bilingual education, particularly French immersion programs, communicative language teaching and testing, and second language acquisition/learning. She has published extensively in these areas. Recently, in her work on the "output hypothesis," she has become interested in the role of collaborative learning in SLA.

Laura S. Miccoli is an assistant professor of English at the Germanic Languages Department at the Federal University of Minas Gerais, Brazil. She has published and given workshops on the use of journals in EFL classrooms. She is currently working toward her doctoral degree in applied linguistics through the Modern Language Centre at OISE.

\section{References}

Allwright, R.L. (1988) Observation in the Language Classroom. London: Longman.

Aronson, E., Blaney, N., Stephan, C., Sikes, J., \& Snap, M. (1978). The jigsaw classroom. Beverly Hills, CA: Sage.

Coelho, E. (1992). Cooperative learning: Foundation for a communicative curriculum. In C. Kessler (Ed.), Cooperative language learning: A teacher's resource book (pp. 31-49). Englewood Cliffs, NI: Prentice Hall.

Fathman, A.K., \& Kessler, C. (1993). Cooperative language learning in school contexts. Annual Review of Applied Linguistics 13, 127-140.

Holt, D.D. (Ed.). (1993). Cooperative learning: A response to linguistic and cultural diversity. Washington, DC: Center for Applied Linguistics.

Horowitz, E.K., \& Young, D.J. (Eds.). (1991). Language anxiety: From theory and research to classroom implications. Englewood Cliffs, NJ: Prentice Hall.

Johnson, D.M. (1992). Approaches to research in second language learning. New York: Longman.

Johnson, D.W., \& Johnson, R.T. (1991). Learning together and alone: Cooperative, competitive, and individualistic learning. Edina, MN: Interaction.

Kagan, S. (1986). Cooperative learning and sociocultural factors in schooling. In California State Department of Education (Ed.), Beyond language: Social and cultural factors in schooling language minority students (pp. 231-298). Los Angeles, CA: Evaluation, Dissemination and Assessment Center, California State University.

Kagan, S. (1989). The structural approach to cooperative learning. Educational Leadership, 47, 12-15.

Kagan, S., \& McGroarty, M. (1993). Principles of cooperative learning for language and content gains. In D.D. Holt (Ed.), Cooperative learning: A response to linguistic and cultural diversity (pp. 47-66). Washington, DC: Center for Applied Linguistics.

Kessler, C. (Ed.). (1992). Cooperative language learning: A teacher's resource book. Englewood Cliffs, NJ: Prentice Hall.

Long, M., \& Porter, P.A. (1985). Group work, interlanguage talk and second language acquisition. TESOL Quarterly, 19, 207-228.

McLaughlin, B. (1990). "Conscious" versus "unconscious" learning. TESOL Quarterly, 24, 617-634.

Miccoli, L.S. (1987). Journal-writing as a feedback and as an EFL-related issues discussion tool. Estudios Germanicos, 8, 59-66. Belo Horizonte: UFMG.

Mulleret, M. (1992). Cooperative learning in the Portuguese-for-Spanish-speakers classroom. Foreign Language Annals, 25, 435-440.

Pica, T., Holliday, L., Lewis, N., \& Morgenthaler, L. (1989). Comprehensible output as an outcome of linguistic demands on the learner. Studies in Second Language Acquisition, 11, 63-90.

Schmidt, R. (1993). Awareness and second language acquisition. Annual Review of Applied Linguistics, 13, 206-226. 
Sharan, Y. \& Sharan, S. (1992). Expanding cooperative learning through group investigation. New York: Teachers College Press.

Slavin, R.E. (1990). Cooperative learning: Theory, research, and practice. Englewood Cliffs, NJ: Prentice Hall Regents.

Slavin, R.E. (1991). Synthesis of research on cooperative learning. Educational Leadership, 48, $71-82$.

Swain, M. (1993). The output hypothesis: Just speaking and writing aren't enough. Canadian Modern Language Review, 50, 158-164.

van Lier, L. (1991). Inside the classroom: Learning processes and teaching procedures. Applied Language Learning, 2, 29-68.

van Lier, L. (1988). The classroom and the language learner. New York: Longman.

\section{Joan Acosta Named to the Order of British Columbia}

Joan Acosta was awarded the Order of British Columbia at a ceremony at Government House, Victoria on June 16 of this year. Joan's accomplishments have helped introduce the joy of the written word to hundreds of thousands of British Columbians.

Born in Guatemala, she taught in Ontario before moving to B.C. in 1979 to become an ESL instructor at Capilano College. Twelve years ago, Joan Acosta was appointed editor of the Westcoast Reader, an ESL source of local, national, and international news stories for adults and teens who are improving their English reading skills. Her vision and determination as the paper's only staff member took the newspaper from a struggling publication with no funding, to a literacy tool highly valued by teachers and treasured today by more than 65,000 new readers.

Joan Acosta's expertise and innovative ideas have been emulated worldwide. As a result, she's in constant demand for workshops across North America. She is the editor of the critically acclaimed Newcomer's Guide to Resources and Services in B.C., has published her own best-selling Coast-to-Coast Reader, and served on boards of several ESL organizations. TESL Canada can be very proud of Joan's accomplishments; this recognition of her contributions is well deserved. 